\title{
Six pelagic seabird species of the North Atlantic engage in a fly-and-forage strategy during their migratory movements
}

\author{
F. Amélineau ${ }^{1, *}$, B. Merkel ${ }^{1,22}$, A. Tarroux ${ }^{2}$, S. Descamps ${ }^{1}$, T. Anker-Nilssen ${ }^{3}$, \\ O. Bjørnstad ${ }^{4}$, V. S. Bråthen ${ }^{3}$, O. Chastel ${ }^{5}$, S. Christensen-Dalsgaard ${ }^{5}$, J. Danielsen ${ }^{6}$, \\ F. Daunt ${ }^{7}$, N. Dehnhard ${ }^{3}$, M. Ekker ${ }^{8}$, K. E. Erikstad ${ }^{2}$, A. Ezhov ${ }^{9}$, P. Fauchald ${ }^{2}$, \\ M. Gavrilo ${ }^{10,11,23}$, G. T. Hallgrimsson ${ }^{12}$, E. S. Hansen ${ }^{13}$, M. P. Harris ${ }^{7}$, M. Helberg ${ }^{14}$, \\ H. H. Helgason ${ }^{1,24}$, M. K. Johansen ${ }^{1}$, J. E. Jónsson ${ }^{15}$, Y. Kolbeinsson ${ }^{16}$, Y. Krasnov ${ }^{9}$, \\ M. Langset ${ }^{3}$, S. H. Lorentsen ${ }^{3}$, E. Lorentzen ${ }^{1}$, M. V. Melnikov ${ }^{17}$, B. Moe ${ }^{3}$, \\ M. A. Newell ${ }^{7}$, B. Olsen ${ }^{6}$, T. Reiertsen ${ }^{2}$, G. H. Systad ${ }^{18}$, P. Thompson ${ }^{19}$,
} T. L. Thórarinsson ${ }^{16}$, E. Tolmacheva ${ }^{20}{ }^{2}$ S. Wanless ${ }^{7}$, K. Wojczulanis-Jakubas ${ }^{21}$, J. Åström ${ }^{3}$, H. Strøm ${ }^{1}$

${ }^{1}$ Norwegian Polar Institute, Fram Centre, 9296 Tromsø, Norway

Full author addresses are given in the Appendix

\begin{abstract}
Bird migration is commonly defined as a seasonal movement between breeding and non-breeding grounds. It generally involves relatively straight and directed large-scale movements, with a latitudinal change, and specific daily activity patterns comprising less or no foraging and more traveling time. Our main objective was to describe how this general definition applies to seabirds. We investigated migration characteristics of 6 pelagic seabird species (little auk Alle alle, Atlantic puffin Fratercula arctica, common guillemot Uria aalge, Brünnich's guillemot $U$. lomvia, black-legged kittiwake Rissa tridactyla and northern fulmars Fulmarus glacialis). We analysed an extensive geolocator positional and saltwater immersion dataset from 29 colonies in the North-East Atlantic and across several years (2008-2019). We used a novel method to identify active migration periods based on segmentation of time series of track characteristics (latitude, longitude, net-squared displacement). Additionally, we used the saltwater immersion data of geolocators to infer bird activity. We found that the 6 species had, on average, 3 to 4 migration periods and 2 to 3 distinct stationary areas during the non-breeding season. On average, seabirds spent the winter at lower latitudes than their breeding colonies and followed specific migration routes rather than non-directionally dispersing from their colonies. Differences in daily activity patterns were small between migratory and stationary periods, suggesting that all species continued to forage and rest while migrating, engaging in a 'flyand-forage' migratory strategy. We thereby demonstrate the importance of habitats visited during seabird migrations as those that are not just flown over, but which may be important for re-fuelling.
\end{abstract}

KEY WORDS: Light-level geolocation · Non-breeding movements $\cdot$ Migration strategies $\cdot$ Dovekies · Common murres $\cdot$ Thick-billed murres

\section{INTRODUCTION}

Migration is observed across a wide range of animal taxa and spatiotemporal scales. It is generally defined

*Corresponding author: francoise.amelineau@gmail.com as a journey at regular times to optimize access to spatiotemporally fluctuating resources, and it usually implies a change in latitude, altitude or depth (Dingle \& Drake 2007). Among birds, migration patterns can

() The authors 2021. Open Access under Creative Commons by Attribution Licence. Use, distribution and reproduction are unrestricted. Authors and original publication must be credited. 
be described as existing along a continuum of 3 main strategies (Fig. 1). The first strategy is based on timeminimization, implying that individuals travel as fast as possible between breeding and wintering areas (Fig. 1A). Such a strategy reduces the risk of spending time in an unfavourable environment and allows an earlier arrival at the breeding or wintering grounds, which can be advantageous if there is competition for resources. In terms of activity, individuals adopting this strategy drastically change their daily activity patterns during migration to spend more time in flight and not forage (Newton 2007). This timeminimization strategy is common among passerines, waterfowl and shorebirds (Newton 2007). The second strategy, called 'fly-and-forage', is based on energy balance optimization, with individuals migrating more slowly and without drastically changing their daily activity patterns (Fig. 1B). Species adopting the flyand-forage strategy increase the time spent flying during migration, while still foraging regularly along the way (Strandberg \& Alerstam 2007, Klaassen et al. 2008, Dias et al. 2012, Alerstam \& Bäckman 2018). The third strategy, that can be described as an extreme case of the fly-and-forage strategy, consists of birds travelling continuously during the whole nonbreeding period (Fig. 1C), maintaining the same daily activity patterns with no clear dichotomy in behaviour between migratory and stationary segments (Mackley et al. 2010). In addition to these 3 strategies, sea- birds might either have certain preferred migration routes or display dispersive migration, whereby post-breeding movements are multi-directional with respect to the breeding site (likely reflecting a lack of gradient in food availability in the environment, Newton 2007, Guilford et al. 2011, Fayet et al. 2016).

Bird migration has been extensively studied for more than a century (e.g. Cooke 1905). The first revolution in this field was bird ringing (i.e. capturemark-recapture) and the second biologging (Wilson et al. 1992, Ropert-Coudert \& Wilson 2005, Newton 2007). Many important advances in understanding migration using biologging have been achieved in seabirds: the development of miniaturized tracking devices like geolocators or satellite tags has considerably increased our knowledge of seabird nonbreeding distributions (e.g. Block et al. 2011, Frederiksen et al. 2012, 2016, Yurkowski et al. 2019), migratory routes (e.g. González-Solís et al. 2007) and their activity while migrating (e.g. Dias et al. 2012, Klaassen et al. 2012). Seabirds show great variation in non-breeding movements: some are residents and stay in the vicinity of their breeding area during the non-breeding season (Weimerskirch et al. 2015, Berg et al. 2019), while others migrate over large distances, the extreme example being species such as Arctic terns Sterna paradisaea and long-tailed skuas Stercorarius longicaudus changing hemisphere twice a year (10000s km, Egevang et al. 2010, van Bem-
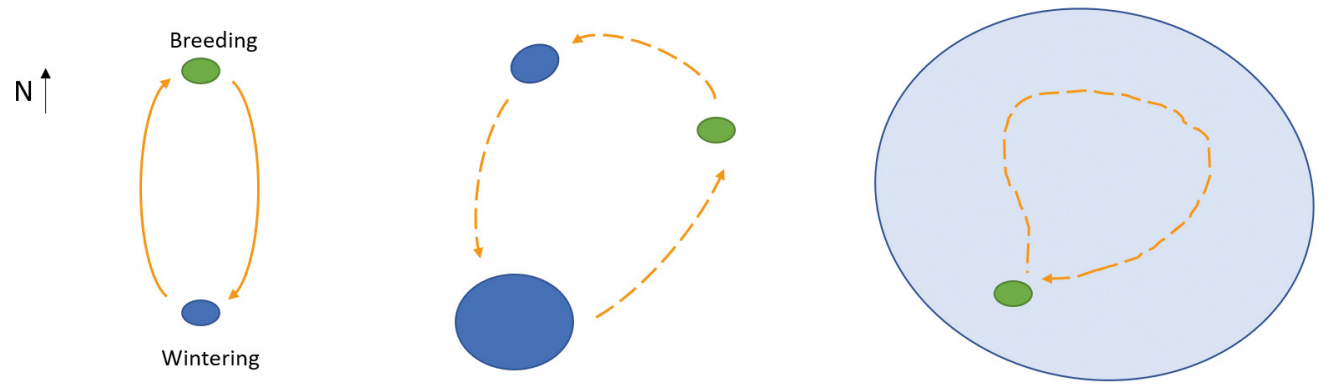

\begin{tabular}{llll}
\hline & A. Time-minimization & B. 'Fly-and-forage' & C. 'Travel continuously' \\
\hline Changes in activity & High & Intermediate & No \\
Changes in speed & High & Intermediate & No \\
$\begin{array}{l}\text { Presence of } \\
\text { stationary segments }\end{array}$ & Yes & Yes & No
\end{tabular}

Fig. 1. Bird migration can be described as a continuum between 3 main strategies. (A) Time-minimization strategy: travelling as fast as possible and changing daily activity patterns to maximize time in flight, no foraging while migrating, movement in a restricted and fixed direction, generally spending the winter at lower latitudes. (B) 'Fly-and-forage' strategy: less pronounced changes in daily activity during migration, continuing to forage and rest, movements more directional during migration, targeting specific non-breeding season areas. (C) 'Travel continuously' strategy: not spending time in a distinct wintering area, instead travelling continuously without changes in daily activity throughout the non-breeding season. Green area: breeding ground; dark blue area: stationary area; light blue area: used during the non-breeding season; solid arrows: migratory movements with a shift in daily activity patterns; dashed arrows: migratory movements where daily routine is maintained. 'Changes' refer to changes between stationary and active migration segments. 
melen et al. 2017). Large variations can also occur within populations of partially migrating species, whereby some individuals remain resident, whilst others migrate (Newton 2012, Pérez et al. 2014, Weimerskirch et al. 2015, Grist et al. 2017).

Migratory birds generally spend the winter in a rather limited area at a lower latitude (Newton 2007). However, this pattern is often more complex in seabirds, which do not necessarily spend the nonbreeding season at lower latitudes (Croxall et al. 2005, Newton 2007, Lorentsen \& May 2012). Furthermore, seabirds often spend time in several discrete areas during the non-breeding season, either by visiting different areas during the autumn and/or the spring or by visiting a series of distinct areas during the winter (e.g. Mosbech et al. 2012, Orben et al. 2018, Merkel et al. 2021 in this Theme Section). Moreover, certain seabirds such as some albatross species travel continuously instead of spending the non-breeding season in well-defined wintering areas (Croxall et al. 2005, Weimerskirch et al. 2015).

Migration strategies may also differ depending on flight modes and foraging strategies (divers vs. surface-feeders). The energetic costs of flight are much higher for flapping than for soaring flight and increase with wing loading for flapping flight, which may limit migration ranges (Hedenström 1993, Newton 2007, Watanabe 2016). In addition, some diving seabirds such as the alcids have wings adapted for dive propulsion, which makes flight more energetically costly and could consequently limit their migration ranges (Elliott et al. 2013). Because they can forage in 3 dimensions, diving seabirds might have access to more resources within a limited geographical area (Furness \& Tasker 2000). Surface feeders, in contrast, need to move further away when resources are depleted at or near the surface within their foraging area. These distinct foraging modes might affect the migratory strategies observed in each group.

While we begin to have a good understanding of the areas in which seabirds spend most of their time in the non-breeding season, there is a need to focus on areas used during active migration periods and to investigate seabird activity during those phases. Here, we define 'active migration periods' as those when individuals travel between the colony and a stationary area or between 2 stationary areas, and 'stationary periods' as those when individuals spend time within a restricted area called stationary area. During active migration periods, birds are particularly vulnerable due to the energetic challenge of sustained flight periods, and/or because migrants often travel through less favourable or even un- favourable habitat (Newton 2007). In particular, the impacts of a deterioration of these areas will vary depending on whether seabirds solely fly over them, or whether they forage and rest during active migration periods. Indeed, improved understanding of seabird migratory behaviour and the identification of potential migration corridors and staging areas are crucial to inform seabird conservation (McFarlane Tranquilla et al. 2013, Frederiksen et al. 2016).

The aim of our study was to provide a description of the general migratory patterns of 6 pelagic seabird species and to evaluate where each species lies on the continuum of migration strategies that we defined as ranging from a time-minimization strategy to a 'continuous travel' strategy (Fig. 1). We took advantage of the SEATRACK dataset (https://seapop. no/en/seatrack/, Fauchald et al. 2019), a multi-year and multi-colony dataset consisting of 4806 geolocator tracks of little auks Alle alle, Atlantic puffins Fratercula arctica (hereafter puffins), common guillemots Uria aalge, Brünnich's guillemots U. lomvia, black-legged kittiwakes Rissa tridactyla (hereafter kittiwakes) and northern fulmars Fulmarus glacialis (hereafter fulmars) from 29 colonies across the NorthEast Atlantic. The 6 species belong to different seabird families and have contrasting foraging strategies. Little auks, puffins and guillemots are Alcidae (hereafter alcids), kittiwakes are Laridae and fulmars are Procellariidae. The alcids are divers, while fulmars and kittiwakes are surface feeders (although fulmars sometimes make short dives, Garthe \& Furness 2001). We investigated whether differences in migratory behaviour could be related to the foraging strategies or to taxonomic family (the latter reflecting morphology and flight mode). Moreover, we assessed whether seabird migration qualifies as dispersive, or whether individuals follow specific routes and target specific wintering areas (Newton 2007).

Depending on where each species fell along the continuum of migratory strategies (Fig. 1), we expected differences in track characteristics, including daily activity, route or wintering latitude. For species adopting a time-minimization strategy, we expected more time spent flying and little or no time spent foraging and resting, with higher movement rates and straighter tracks during active migration segments (Newton 2007). In contrast, for species travelling continuously during the non-breeding season, movement characteristics were predicted to be similar within stationary and active migration segments (Newton 2007). Intermediate variations in activity were expected for species that adopted a fly-andforage strategy (Dias et al. 2012). 


\section{MATERIALS AND METHODS}

\subsection{Fieldwork}

Fieldwork was conducted at 29 colonies of the North-East Atlantic in Norway, Russia, Iceland, the Faroe Islands and the United Kingdom (Fig. S1 in the Supplement at www.int-res.com/articles/suppl/ m676p127_supp.pdf), between 2006 and 2019. Geolocators were attached to a plastic leg ring, with a mean \pm SD total weight of $0.61 \pm 0.23 \%$ of bird body mass for all species (range: $0.23-1.58 \%$; Tables S2 \& S3). Individuals were equipped during the breeding season and recaptured in a subsequent breeding season (median deployment duration: 1 year, range: 1-5 yr), with some individuals equipped more than once (median number of deployments per individual: 1, range: 1-7). Geolocators were produced by the British Antarctic Survey (BAS), Migrate Technology and Biotrack. We analysed 4806 tracks (1 yr period from one breeding season to the next) from 2410 individuals, with a median of 2 tracks recorded per individual (range: 1-8 tracks per individual). Details on the logger models and number of tracks per colony are available in Tables S1 \& S2 in the Supplement.

\subsection{Characterisation of tracks: automatic processing \& IRMA}

The protocol used to estimate positions from raw light data is described in Bråthen et al. (2021). In brief, a threshold method was used (Lisovski et al. 2020), and raw positions were filtered with speed, angle and distribution filters. Equinox periods (8 Sep20 Oct and 20 Feb-3 Apr) were removed due to inaccuracy in the estimated latitudes during these times (Frederiksen et al. 2012). In addition, no positions could be obtained when birds were above $63^{\circ} \mathrm{N}$ during summer solstice and $70^{\circ} \mathrm{N}$ during winter solstice due to the midnight sun and polar night, respectively. To avoid gaps in the tracks, missing locations were interpolated based on the Informed Random Movement Algorithm (IRMA, Text S1 in the Supplement), following an approach originally proposed by Technitis et al. (2015). This method takes into account complementary information on light levels, land masks and saltwater immersion data to infer presence at the colony, and longitude during the equinoxes to replace the missing locations with the most plausible estimates, thereby reducing the sampling bias in our dataset to a minimum (Fauchald et al. 2019).

\subsection{Two-step identification of migratory and stationary periods}

We developed a 2-step approach based on timeseries segmentation methods to separate periods of active migration from stationary periods. This approach is computationally efficient and flexible enough to be applied to a wide range of migratory behaviours. It is based on the net-squared displacement (NSD, Bunnefeld et al. 2011) and does not make use of the distributions of step length, turning angles or activity; the different movement indices considered in the analyses are thus independent of the criteria used to categorize the trajectories into active migration or stationary segments. The first step consisted of defining stationary periods using Lavielle segmentation (Calenge 2006, Barraquand \& Benhamou 2008). This segmentation identified distinct periods for each time series of the following parameters: longitude, latitude and net-squared colony distance (NSCD, defined here as the NSD relative to the colony). The cut-offs defined by this first step correspond to the midpoint of an active migration segment (Fig. 2A-C). To further identify the beginning and the end of each active migration segment, we used an automated classification method based on NSD (Fig. 2D-F) available in the R package 'migrateR' (Spitz et al. 2017). Two examples of segmentation are shown in Fig. 2 (kittiwake) and Fig. S2 (Brünnich's guillemot).

\subsubsection{Lavielle segmentation}

Lavielle segmentation finds the best segmentation of a time series, assuming that the mean and/or the variance is constant within a segment and varies between segments (Barraquand \& Benhamou 2008). We applied this method to 3 time series: longitude, latitude and NSCD (Fig. 2A-C), using the 'lavielle' function in the 'adehabitatLT' package (Calenge 2006). We supposed that only the mean varied among segments. Providing a maximum number of segments $\left(K_{\max }\right)$, the function finds the best number of segments $\left(K_{\mathrm{opt}} \leq K_{\max }\right)$ to minimise a contrast function (Lavielle 2005). The minimum duration of a segment $\left(L_{\min }\right)$ was set to $5 \mathrm{~d}$, and $K_{\max }$ was set to 15 , based on recommendations in Barraquand \& Benhamou (2008) to set this value to $2-4 \times$ the expected number of segments. The method was applied to 3 time series to increase the probability of detecting changes in bird behaviours and thus of detecting migratory and stationary segments. As the segment 

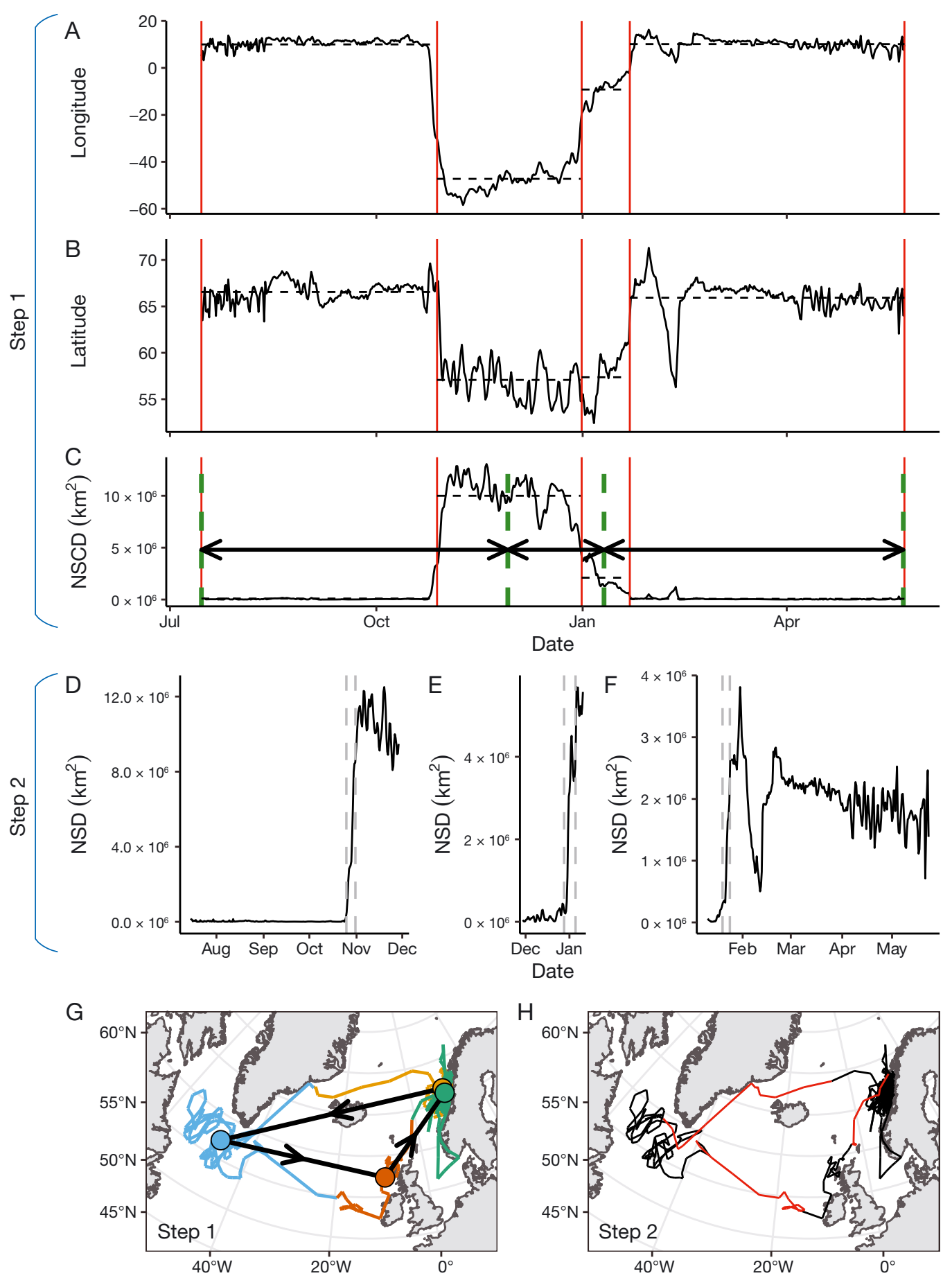

Fig. 2. Example of Lavielle and 'migrateR' segmentation for 1 kittiwake from Sør-Gjæslingan (Sklinna keysite), Norway. Step 1: The Lavielle segmentation delimits the stationary periods; the limits represent the midpoint of a migratory movement. (A-C) Time series used for Lavielle segmentation: longitude, latitude and net-squared colony distance (NSCD). Red segments: Lavielle segmentation cut-offs, in the middle of a migratory movement. Black dotted lines: mean value for each Lavielle segment. Step 2: 'MigrateR' is used to delimit the start and end of each active migration segment. 'MigrateR' models the netsquared displacement (NSD) from one stationary area to the next, it is therefore necessary to run it on 'migrateR' segments comprising the migratory movement and stationary periods preceding and following the movement. 'MigrateR'-segments are delimited by the middle of Lavielle segments (the first and last Lavielle segments are fully included in the first and last 'migrateR'-segments, respectively). Green dashed lines: cut-offs used for the 3 'migrateR'-segments. Double-headed arrows in (C): the 3 'migrateR'-segments represented in D, E and F. (D-F) NSD for the 3 'migrateR'-segments. Dotted lines: start and end of active migration segments determined by 'migrateR'. (G) Lavielle segments (yellow, blue, orange, green) that emphasize stationary areas. Circles: centroids of the stationary periods; arrows: simplified migration tracks (link between the centroids).

$(\mathrm{H})$ Active migration segments identified by 'migrateR' in red 
cut-offs varied slightly among time series for the same stationary period, we calculated a mean event for dates that were $<7 \mathrm{~d}$ apart in order to remove redundant detections of the same event. Setting this threshold to a lower value created very short Lavielle segments when birds were moving, which meant the next step failed to find active migration segments correctly. We used the centroid of the positions within each Lavielle segments to pinpoint stationary areas. We then mapped simplified trajectories linking centroids in order to visualize and compare migration patterns among species and colonies (see example in Fig. 2G).

\subsubsection{Delimiting active migration segments with 'migrateR'}

As Lavielle segmentation delimits stationary periods with a cut-off point in the middle of a migratory movement (Fig. 2A-C), we used 'migrateR' (Fig. 2D-F) to detect the beginning and end of each active migration segment (Spitz et al. 2017). 'MigrateR' is an automated model-driven classification and quantification of migratory behaviour based on NSD patterns (Spitz et al. 2017). It uses 5 different migration models representing 5 possible behaviours: migrant, mixed migrant, disperser, nomad or resident (Bunnefeld et al. 2011, Spitz et al. 2017). 'MigrateR' was developed for ungulates and could not easily be used for seabird, because it only allowed 1 stationary site during the non-breeding season. We thus only used it to calculate migration dates. We adapted the method to fit a 'disperser' model (i.e. movement with no return) to every segment of each track comprising a movement encircled by 2 stationary periods (Fig. 2D-F). The disperser model fits a sigmoid function to the NSD. As the migratory periods are overlapping between 2 Lavielle segments, we first re-segmented each track by cutting at the middle of each Lavielle segment. This procedure allowed each of the 'migrateR' segments to contain the second half of one Lavielle segment and the first half of the next, i.e. 2 stationary periods bounding a migratory movement (Fig. 2C). 'MigrateR' was run on each 'migrateR'-segment (Fig. 2D-F), and the NSD was calculated from the centroid of the first Lavielle segment to represent the starting location of the migratory movement. The equation of the sigmoid curve of the estimated NSD $\left(\mathrm{NSD}_{\mathrm{e}}\right)$ was:

$$
\mathrm{NSD}_{\mathrm{e}}=\frac{\delta}{1+\exp \left(\frac{\theta-t}{\phi}\right)}
$$

where $\delta$ was the squared distance between the 2 stationary areas, $t$ the time since start, $\theta$ the time of the midpoint of the movement and $\phi$ the time required to complete $1 / 2$ to $3 / 4$ of the migratory movement.

Within 'migrateR', we also fitted the resident (no large-scale displacement) and nomadic (constant movement) models (see Spitz et al. 2017 for detailed equations). If the fit (assessed with Akaike's Information Criterion; AIC) was better for resident or nomadic than for disperser models, we assumed that the 'migrateR'-segment contained no active migration segment, as no clear movement pattern was detected.

Several filters were applied to avoid false detection of active migration segments. We excluded 'migrateR'segments (i.e. the active migration segment and half of the stationary periods preceding and following the active migration segment) that were too short $(<15$ positions) to run the function. Furthermore, we excluded segments for which the disperser model did not converge, and segments for which start and end dates of active migration segments were out of range of the 'migrateR'-segment dates. We considered there to be no migration when the distance between the centroids of successive stationary areas was $<200 \mathrm{~km}$ due to the precision of geolocation (Phillips et al. 2004).

By default, NSD was calculated from the centroid of the first Lavielle segment (the stationary period preceding the active migration segment). If the disperser model did not converge, or if the migratory dates found were out of range, we used the 'findrloc' function of the 'migrateR' package to find a more appropriate starting date within the first half of the 'migrateR'segment. This step allows some flexibility to find the appropriate active migration segments (Spitz et al. 2017). We extracted estimated migratory dates, corresponding to $10 \%$ and $90 \%$ of the movement completion, with the 'mvt2dt' function $(p=0.10)$. Periods at the colony were kept in the segmentation process because 'migrateR' needs a stationary period prior to departure and after arrival to fit the sigmoid model. To analyse movement characteristics and activity during the nonbreeding period only, we excluded the first and last stationary segments of each individual's yearly track and the mean breeding dates at the colony level based on saltwater immersion data (Fauchald et al. 2019).

\subsection{Sinuosity index, apparent movement rates and latitudinal changes}

As the segmentation method used to delimit active migration segments is not directly based on speed 
and sinuosity, we used these 2 parameters to validate the method. We tested whether active migration segments were straighter than stationary segments and whether apparent movement rate was higher during migration. For the sinuosity, tracks were first rediscretised at a constant step length $(p)$ of $50 \mathrm{~km}$. We calculated the sinuosity index defined by Benhamou (2004) at the segment level, with the 'trajr' package (McLean \& Volponi 2018):

$$
\operatorname{sinuosity}_{i}=\left[p\left(\frac{1+c}{1-c}+b^{2}\right)\right]^{-0.5}
$$

where $i$ was the segment index, $c$ the mean cosine of turning angles and $b$ the coefficient of variation of the step length. Apparent movement rate (in $\mathrm{km} \mathrm{h}^{-1}$ ) was calculated for each location based on the distance covered and time spent moving to the next location. The apparent movement rate includes both migratory movements, day-to-day movements and the geolocation error. IRMA-generated locations were removed from the movement rate analyses to avoid potential bias. The mean apparent movement rate per segment was used for statistical models.

We also compared the latitude of the stationary segments with the latitude of the colony to assess whether seabirds had a dispersive migration (in this case we expected the average latitude to be the same as the colony latitude) or whether they spend the non-breeding season at different latitudes than their colonies. For this comparison, we calculated a difference in latitude between the colony and the centroid for the stationary segment. A positive value meant that the bird was at a lower latitude than its colony. We compared 3 seasons defined according to bird movements: autumn (AugOct), winter (Nov-Jan) and spring (Feb-Apr).

\subsection{Comparison of migratory patterns}

Given a considerable variety in the observed migration patterns across the seabird species that we investigated, we used an additional approach to classify migration, based on the variance of the logarithm of the first passage time (FPT, measuring how variable the track structure was, Fauchald \& Tveraa 2003) and the maximum NSCD (indicating how far individuals went from their colonies). A high variance of $\log$ (FPT) indicates a heterogenous track with movement patterns occurring over a wide range of spatial scales (e.g. area-restricted movements with straighter movements in between). A low variance of $\log (\mathrm{FPT})$ is indicative of a more homogenous track, e.g. the track of an individual staying close to the colony in the winter with a sinuous track, or the track of an individual moving over larger distances at a constant rate during the entire non-breeding period with no clear area-restricted search behaviour. The NSCD helps disentangle the latter 2 patterns by separating birds according to the maximum distance to the colony that was reached (individuals moving over larger distances at a constant rate having a higher NSCD than birds staying close to their colonies). NSCD was calculated using the great circle distance between each location and the colony. The maximum NSCD per track was used for the analyses. To calculate the first passage time, we used the function 'fpt' from the 'adehabitatLT' package (Calenge 2006). For sinuosity calculations, the tracks were first rediscretised to a constant step length of $50 \mathrm{~km}$. A radius of $250 \mathrm{~km}$ was used to compute FPT and was chosen for all species so that the variance in $\log (\mathrm{FPT})$ was maximised when plotting against the radius (Fauchald \& Tveraa 2003). To take into account the different number of tracks per colony, we first calculated the mean per colony and then the mean and standard deviation per species.

\subsection{Analysis of saltwater immersion data}

Saltwater immersion data were recorded with different modes depending on the logger type. Of the loggers used, $66.1 \%$ recorded the sum of wet events measured every $3 \mathrm{~s}$ over a 10 min interval, $29.3 \%$ every 30 s over a 10 min interval, $0.3 \%$ every 6 s over a $5 \mathrm{~min}$ interval and $0.01 \%$ every $30 \mathrm{~s}$ over a $4 \mathrm{~h}$ interval (Table S4). The 2 latter recording modes were excluded from the statistical analyses because they were only used for 1 species; so, we could not simultaneously test for effects of species and recording mode (Table S4). To compare data between different recording modes, saltwater immersion data were first standardized by dividing each value by the maximum saltwater immersion value that the logger could record. This gave a value between 0 (logger dry during the entire recording interval) and 1 (logger wet during the entire recording interval). Each interval was then allocated to a category: wet (standardized value $<0.05$ ), dry (standardized value $>0.95)$ and intermediate $(0.05 \leq$ standardized value $\leq 0.95$ ). These categories may be used as proxies for behaviour, with dry = flying, wet = resting and intermediate $=$ foraging (Lecomte et al. 2010, Fayet et al. 2017). We then calculated the time spent in each category per active migration and stationary segments. 


\subsection{Statistical analyses}

All statistical analyses were performed using $\mathrm{R}$ version 4.0.2 and the 'nlme' package (Pinheiro et al. 2020, R Core Team 2020). We used generalized linear mixed-effects models ('lme' function) with colony, individual identity and tracking year defined as random factors, following the approach of Zuur \& Ieno (2016). We worked at the segment level: for sinuosity, time spent wet, dry or intermediate, and latitude difference, we had 1 value per segment; for apparent movement rate, we calculated the mean value per segment. For apparent movement rate, sinuosity and time spent wet, dry or intermediate, we compared models with and without the segment type variable to assess differences between active migration and stationary periods. We then considered models with species and with the interaction between species and segment type to assess whether observed average patterns differ among species. We also assessed the potential variations among families (3 levels: Laridae, Procellariidae and Alcidae) and foraging strategies (2 levels: divers, surface feeders), replacing the species factor by family or foraging strategy in the 2 models mentioned above. Model selection was based upon AIC. The model with the lowest AIC was considered as the most appropriate to explain the data. If 2 models had a $\triangle$ AIC $<2$, the more parsimonious model was retained (Burnham \& Anderson 2002). The distribution of the residuals against fitted values was checked, and a transformation of the data was done in case of clear lack of normality or homoscedasticity. The apparent movement rate was therefore log-transformed, and the sinuosity index was transformed using an arcsine square root transformation. The saltwater immersion data were analysed for each category (wet, dry, intermediate) separately. For each segment, the time spent in one activity was dependent on the total duration of the segment, so we used the residual of the linear regression between the time spent wet, dry or intermediate per segment, with the duration of the segment as a response variable. We also included saltwater immersion recording mode as a fixed factor (2 levels: 3s_10min and 30s_10min), as different recording frequencies could influence the classification.

For the difference in latitude between the centroids of stationary periods and the colony, the approach was the same, but the fixed factors differed: we compared models containing the season (3 levels: autumn, winter and spring), species and their interaction as fixed effects, and random effects of colony, individual identity and tracking year. We also tested whether foraging strategy or family were better predictors than species.

For all the analyses or maps requiring a projection of the data we used an azimuthal equidistant projection centred on the centroid of all the positions of our dataset $\left(64.26091^{\circ} \mathrm{N}, 13.0964^{\circ} \mathrm{W}\right)$. Unless otherwise mentioned, means are presented with their standard error.

\section{RESULTS}

\subsection{Number of active migration segments and stationary periods}

The mean number of active migration segments per non-breeding season ranged between a minimum of 3.11 for kittiwakes and a maximum of 4.05 for puffins (Table 1). Thus, on average, individuals spent time in 2 to 3 stationary areas during the nonbreeding season. The average duration of active migration segments was similar among species, with a minimum of $10.27 \mathrm{~d}$ for fulmars and a maximum of $13.10 \mathrm{~d}$ for puffins (Table 1). In total, between 13.2\% (47 d, fulmars) and $23.8 \%$ ( $84 \mathrm{~d}$, little auks) of the year was spent migrating. Active migration segments occurred mostly at the end of the summer, in the

Table 1. Characteristics of active migration segments (AMSs) and stationary segments. Data are mean \pm SE. Distance covered: sum of the daily distances covered for each active migration segment

\begin{tabular}{|c|c|c|c|c|c|c|}
\hline Species & $\begin{array}{l}\text { No. of } \\
\text { AMSs } \\
\text { per year }\end{array}$ & $\begin{array}{l}\% \text { of the } \\
\text { year in } \\
\text { migration }\end{array}$ & $\begin{array}{c}\text { AMS } \\
\text { duration (d) }\end{array}$ & $\begin{array}{c}\text { Apparent moven } \\
\text { AMS }\end{array}$ & $\begin{array}{l}\text { nt rate }\left(\mathrm{km} \mathrm{h}^{-1}\right) \\
\text { Stationary } \\
\text { segments }\end{array}$ & $\begin{array}{c}\text { Distance } \\
\text { covered }(\mathrm{km})\end{array}$ \\
\hline Little auk & $3.55 \pm 0.08$ & $23.81 \pm 0.58$ & $12.79 \pm 0.33$ & $5.50 \pm 0.04$ & $5.17 \pm 0.02$ & $1449 \pm 35$ \\
\hline Atlantic puffin & $4.05 \pm 0.05$ & $19.15 \pm 0.35$ & $13.10 \pm 0.23$ & $6.25 \pm 0.03$ & $5.47 \pm 0.01$ & $1631 \pm 28$ \\
\hline Common guillemot & $3.21 \pm 0.05$ & $14.45 \pm 0.33$ & $12.22 \pm 0.24$ & $5.28 \pm 0.02$ & $4.80 \pm 0.01$ & $1239 \pm 22$ \\
\hline Brünnich's guillemot & $3.34 \pm 0.05$ & $15.76 \pm 0.34$ & $12.33 \pm 0.24$ & $5.74 \pm 0.03$ & $4.87 \pm 0.01$ & $1364 \pm 22$ \\
\hline Black-legged kittiwake & $3.11 \pm 0.03$ & $14.01 \pm 0.21$ & $12.08 \pm 0.16$ & $12.37 \pm 0.04$ & $9.39 \pm 0.01$ & $3137 \pm 33$ \\
\hline Northern fulmar & $3.76 \pm 0.06$ & $13.19 \pm 0.32$ & $10.27 \pm 0.23$ & $11.62 \pm 0.06$ & $9.73 \pm 0.03$ & $2356 \pm 52$ \\
\hline
\end{tabular}


autumn and in the spring (Fig. S3) but could also occur at any time for all species during the non-breeding season. The mean distance covered during active migration segments varied among species (Table 1). Shorter distances were observed in alcids (range of means per species: $1239-1631 \mathrm{~km}$ ), while longer distances were observed in fulmars and kittiwakes (means: 2356 and $3137 \mathrm{~km}$, respectively, Table 1). Descriptive values per colony are available in Table S5.

\subsection{Apparent movement rate and sinuosity}

All species had a higher apparent movement rate during active migration than during stationary segments (Fig. 3A, Table S6). The slowest species was the common guillemot with a movement rate of 5.28 $\pm 0.02 \mathrm{~km} \mathrm{~h}^{-1}$ during migration and $4.80 \pm 0.01 \mathrm{~km}$ $\mathrm{h}^{-1}$ during stationary periods, and the fastest species was the kittiwake with a movement rate of $12.37 \pm$ $0.04 \mathrm{~km} \mathrm{~h}^{-1}$ during migration and $9.39 \pm 0.01 \mathrm{~km} \mathrm{~h}^{-1}$ during stationary periods. The apparent movement rate was between $6.5 \%$ (little auks) and $31.8 \%$ (kittiwakes) higher in active migration than in stationary segments (Table 1, Fig. 3A). The best model explaining differences in apparent movement rate included segment type, species and their interaction (Tables 2 \& S6).

For all species, the sinuosity index was higher for stationary periods than active migration periods (Fig. 3B, Table S7), but this effect varied among species; in particular, sinuosity was always higher for alcids than kittiwakes and fulmars (Fig. 3B). Sinuos- ity was best explained by the model with segment type, species and their interaction (Table $2 \&$ S7). Neither foraging strategy (diver or surface feeder) or family were retained in models explaining the apparent movement rate or the sinuosity (Table 2 ).

\subsection{Wintering latitudes}

On average, all 6 species were at lower latitudes during the winter months (Nov-Jan) compared to the latitudes of their summer breeding colonies (Fig. 4, Table S8). In autumn and spring, little auks, Brünnich's guillemots and kittiwakes were at lower latitudes, while common guillemots and fulmars were at similar latitudes to their colonies (Fig. 4). Puffins were at similar latitudes to their colonies in the autumn but at lower latitudes in the spring (Fig. 4). The highest latitudinal differences in the winter were observed for kittiwakes and little auks $\left(15.40 \pm 2.10^{\circ} \mathrm{N}\right.$ and $9.75 \pm 1.96^{\circ} \mathrm{N}$, respectively), and the smallest for common guillemots and fulmars $\left(0.89 \pm 0.54^{\circ} \mathrm{N}\right.$ and $2.06 \pm 0.84^{\circ} \mathrm{N}$ respectively, Fig. 4). The model that best explained these differences in latitude during the non-breeding season included season, species and their interaction term (Table $2 \&$ S8).

\subsection{Migration patterns}

To visualise migration routes, we provide simplified representations of individual tracks by plotting the centroid of the stationary areas (Figs. 2G, 5 \& S4).
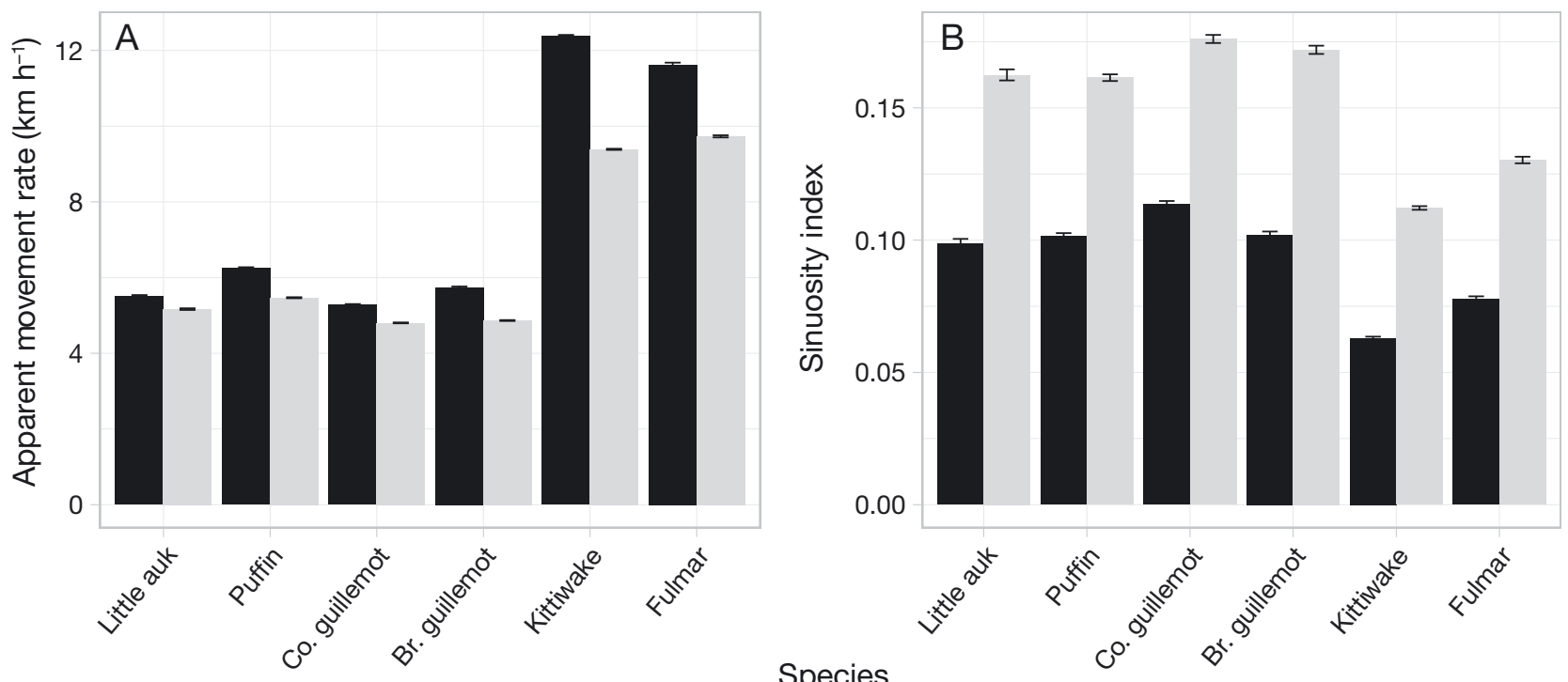

Fig. 3. Mean \pm SE (A) apparent movement rate and (B) sinuosity index during active migration (black) and stationary periods (light grey) 


\begin{tabular}{|c|c|c|c|}
\hline Predictors (fixed effects) & $\mathrm{df}$ & AIC & $\Delta \mathrm{AIC}$ \\
\hline \multicolumn{4}{|l|}{ (A) Apparent movement rate } \\
\hline Intercept & 5 & 24869.48 & 4259.92 \\
\hline Segment type & 6 & 23634.61 & 3025.05 \\
\hline Segment type + species & 11 & 20906.71 & 297.15 \\
\hline Segment type ${ }^{*}$ species & 16 & 20609.56 & 0.00 \\
\hline Segment type + foraging strategy & 7 & 21063.62 & 454.06 \\
\hline Segment type ${ }^{*}$ foraging strategy & 8 & 20825.87 & 216.31 \\
\hline Segment type + family & 8 & 20964.21 & 354.65 \\
\hline Segment type ${ }^{*}$ family & 10 & 20687.67 & 78.11 \\
\hline \multicolumn{4}{|l|}{ (B) Sinuosity } \\
\hline Intercept & 5 & -47707.34 & 9209.11 \\
\hline Segment type & 6 & -55576.71 & 1339.74 \\
\hline Segment type + species & 11 & -56893.38 & 23.07 \\
\hline Segment type ${ }^{*}$ species & 16 & -56916.45 & 0.00 \\
\hline Segment type + foraging strategy & 7 & -56746.08 & 170.37 \\
\hline Segment type ${ }^{*}$ foraging strategy & 8 & -56758.15 & 158.30 \\
\hline Segment type + family & 8 & -56829.84 & 86.61 \\
\hline Segment type ${ }^{*}$ family & 10 & -56840.59 & 75.86 \\
\hline \multicolumn{4}{|l|}{ (C) Latitude difference } \\
\hline Intercept & 5 & 91030.31 & 3235.63 \\
\hline Season & 7 & 90301.94 & 2507.26 \\
\hline Season + species & 12 & 88633.74 & 839.06 \\
\hline Season ${ }^{*}$ species & 22 & 87794.68 & 0.00 \\
\hline Season + foraging strategy & 8 & 89459.67 & 1664.99 \\
\hline Season ${ }^{*}$ foraging strategy & 10 & 89110.17 & 1315.49 \\
\hline Season + family & 9 & 88721.64 & 926.96 \\
\hline Season ${ }^{*}$ family & 13 & 88027.79 & 233.11 \\
\hline \multicolumn{4}{|l|}{ (D) Time spent wet } \\
\hline Intercept & 5 & 295248.4 & 468.10 \\
\hline Mode & 6 & 295075 & 294.70 \\
\hline Segment type + mode & 7 & 295012.8 & 232.50 \\
\hline Segment type + species + mode & 12 & 294946.5 & 166.20 \\
\hline Segment type ${ }^{*}$ species + mode & 17 & 294784.2 & 3.90 \\
\hline Segment type + foraging strategy + mode & 8 & 294998.6 & 218.30 \\
\hline Segment type ${ }^{*}$ foraging strategy + mode & 9 & 294944.1 & 163.80 \\
\hline Segment type + family & 9 & 294948.1 & 167.80 \\
\hline Segment type ${ }^{*}$ family & 11 & 294780.3 & 0.00 \\
\hline \multicolumn{4}{|l|}{ (E) Time spent dry } \\
\hline Intercept & 5 & 277087.7 & 358.00 \\
\hline Mode & 6 & 277076.4 & 346.70 \\
\hline Segment type + mode & 7 & 276979.7 & 250.00 \\
\hline Segment type + species + mode & 12 & 276979.6 & 249.90 \\
\hline Segment type ${ }^{*}$ species + mode & 17 & 276734.6 & 4.90 \\
\hline Segment type + foraging strategy + mode & 8 & 276981.6 & 251.90 \\
\hline Segment type ${ }^{*}$ foraging strategy + mode & 9 & 276839 & 109.30 \\
\hline Segment type + family & 9 & 276980.8 & 251.10 \\
\hline Segment type ${ }^{*}$ family & 11 & 276729.7 & 0.00 \\
\hline \multicolumn{4}{|l|}{ (F) Time spent intermediate } \\
\hline Intercept & 5 & 275955.5 & 316.50 \\
\hline Mode & 6 & 275754.1 & 115.10 \\
\hline Segment type + mode & 7 & 275754.2 & 115.20 \\
\hline Segment type + species + mode & 12 & 275658.1 & 19.10 \\
\hline Segment type ${ }^{*}$ species + mode & 17 & 275639 & 0.00 \\
\hline Segment type + foraging strategy + mode & 8 & 275727.2 & 88.20 \\
\hline Segment type ${ }^{*}$ foraging strategy + mode & 9 & 275727.5 & 88.50 \\
\hline Segment type + family & 9 & 275671.5 & 32.50 \\
\hline Segment type ${ }^{*}$ family & 11 & 275648.9 & 9.90 \\
\hline
\end{tabular}

Table 2. Relative performance of models of movement characteristics and activity as functions of segment type. Response variables are (A) apparent movement rate, (B) sinuosity, (C) latitude difference between colony and stationary area (see Section 2.4) and time spent (D) wet (flying), (E) dry (resting), and $(F)$ intermediate (foraging; see Section 2.6). Factors-segment type: active migration versus stationary segments; foraging strategy: surface feeders versus divers; family consists of Alcidae, Laridae and Procellariidae; mode: activity recording mode (for activity only, models D-F)

Such simplified tracks do not represent the actual route followed by individuals but outline general patterns. For puffins, the simplified representations of their tracks suggest that birds from some colonies (the Faroe Islands, Grimsey, Papey, Røst) followed a specific route, whilst those from other colonies went in multiple directions (Fig. 5). Examples for other species and colonies are presented in Fig. S4. For most species and colonies, individuals did not migrate in all possible directions (dispersive migration) but rather had preferential routes and targeted one or more specific areas (Fig. S4).

Kittiwakes had the most pronounced long-distance migration of all 6 species (Figs. 6 \& S5). Among alcids, little auks and puffins migrated over longer distances and had lower variances of $\log (\mathrm{FPT})$ than the 2 guillemot species (Figs. 6 \& S5).

\subsection{Time spent wet, dry or intermediate in active migration vs. stationary periods}

For the 4 alcids, differences in time spent wet, dry or intermediate between active migration and stationary segments were minor (Fig. 7, Tables S9S11). Conversely, differences were higher for fulmars and kittiwakes: during active migration segments, the average time spent dry (flying proxy) increased by $26.8 \%$ for fulmars and $28.3 \%$ for kittiwakes; the average time 


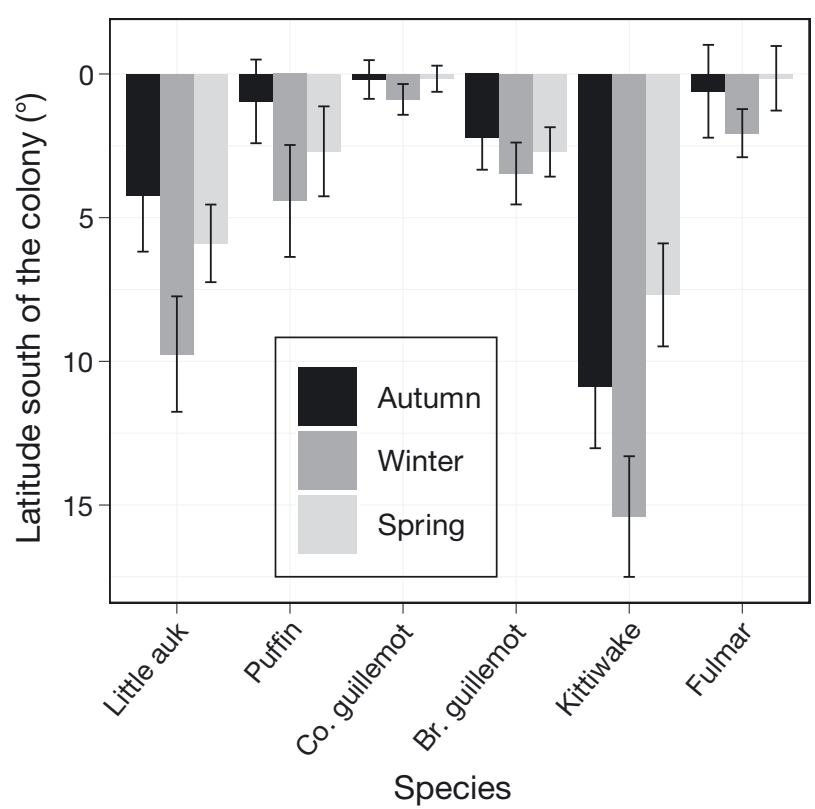

Fig. 4. Mean \pm SE differences in latitude between colony and stationary areas (centroid of the Lavielle segments). Positive value: stationary areas are at lower latitudes than the colony. Seasons are based on bird movements rather than climate - autumn: Aug-Oct; winter: Nov-Jan; spring: Feb-Apr. Values were first averaged by colonies and then by species to consider the different number of tracks among colonies

spent wet (resting proxy) decreased by $12.2 \%$ for fulmars and $9.2 \%$ for kittiwakes, and the average time spent intermediate (foraging proxy) increased by $2.6 \%$ for fulmars and decreased by $4.7 \%$ for kittiwakes (Tables S9-S11, Fig. 7). The models that best explained the time spent wet and the time spent dry had an effect of segment type, family and their interaction (Tables 2, S9 \& S10). The model that best explained the time spent intermediate included segment type, species and their interaction (Tables 2 \& S11).

\section{DISCUSSION}

Using a unique dataset of 6 pelagic species from 29 colonies of the North-East Atlantic, we found that the 6 pelagic seabird species had a fly-and-forage migration strategy and generally had preferred migration routes rather than a dispersive migration. Activity data revealed that they continued to exhibit behavioural patterns consistent with foraging and resting while migrating. The species spent 13 to $23 \%$ (47 to $84 \mathrm{~d}$ ) of the year migrating, and typically performed 3 to 4 active migration segments and spent time in 2 or more distinct stationary areas.

\subsection{Daily activity patterns during active migration periods}

The 6 species did not drastically change their daily activity during active migration periods compared to stationary periods and only slightly increased their daily distance covered. During the active migration segments, kittiwakes and fulmars spent more time in flight and less time resting, and they continued to forage. In contrast, for the 4 alcid species, changes in activity between active migration and stationary segments were very small. These results should be interpreted with caution, because using wet, dry and intermediate categories to assess activity has limitations for alcids: they can tuck their leg in among the feathers when resting, resulting in potential dry recordings that do not correspond to flight behaviour (Linnebjerg et al. 2014, Fayet et al. 2016). They also dive when foraging, and thus their loggers may be mostly wet instead of intermediately wet and dry (but see Fayet et al. 2016, 2017).

These results helped us place the 6 species along the continuum between time-minimization and flyand-forage strategies. The data certainly did not fit the time-minimization hypothesis corresponding to a rapid journey through a potentially non-favourable environment. Instead, the small differences in daily routine that we observed suggest that alcids, kittiwakes and fulmars had a fly-and-forage strategy, with some small increases in time spent flying and decreases in time spent foraging during active migration segments (Fig. 1). While fulmars and kittiwakes appeared to best fit the definition of 'fly-andforage', alcids showed almost no change in behaviour and were thus slightly closer to the 'travel continuously' end of the spectrum. Thus, both activity data and our method's detection of stationary and active migration segments support a fly-and-forage strategy in all species. Similar fly-and-forage migration has been observed in other seabirds such as Cory's shearwaters and lesser black-backed gulls (Dias et al. 2012, Klaassen et al. 2012). It is also commonly observed in raptors (Strandberg \& Alerstam 2007, Hadjikyriakou et al. 2020) and in some passerines such as Bank swallows (Imlay et al. 2020). One prerequisite for the fly-and-forage strategy is that migrants travel over habitats where they can still forage. This strategy might be particularly advantageous for species that can exploit resources discovered as they fly over them while migrating and is expected to be common among seabirds, as well as in terrestrial species able to encounter prey while flying (Alerstam \& Bäckman 2018). 

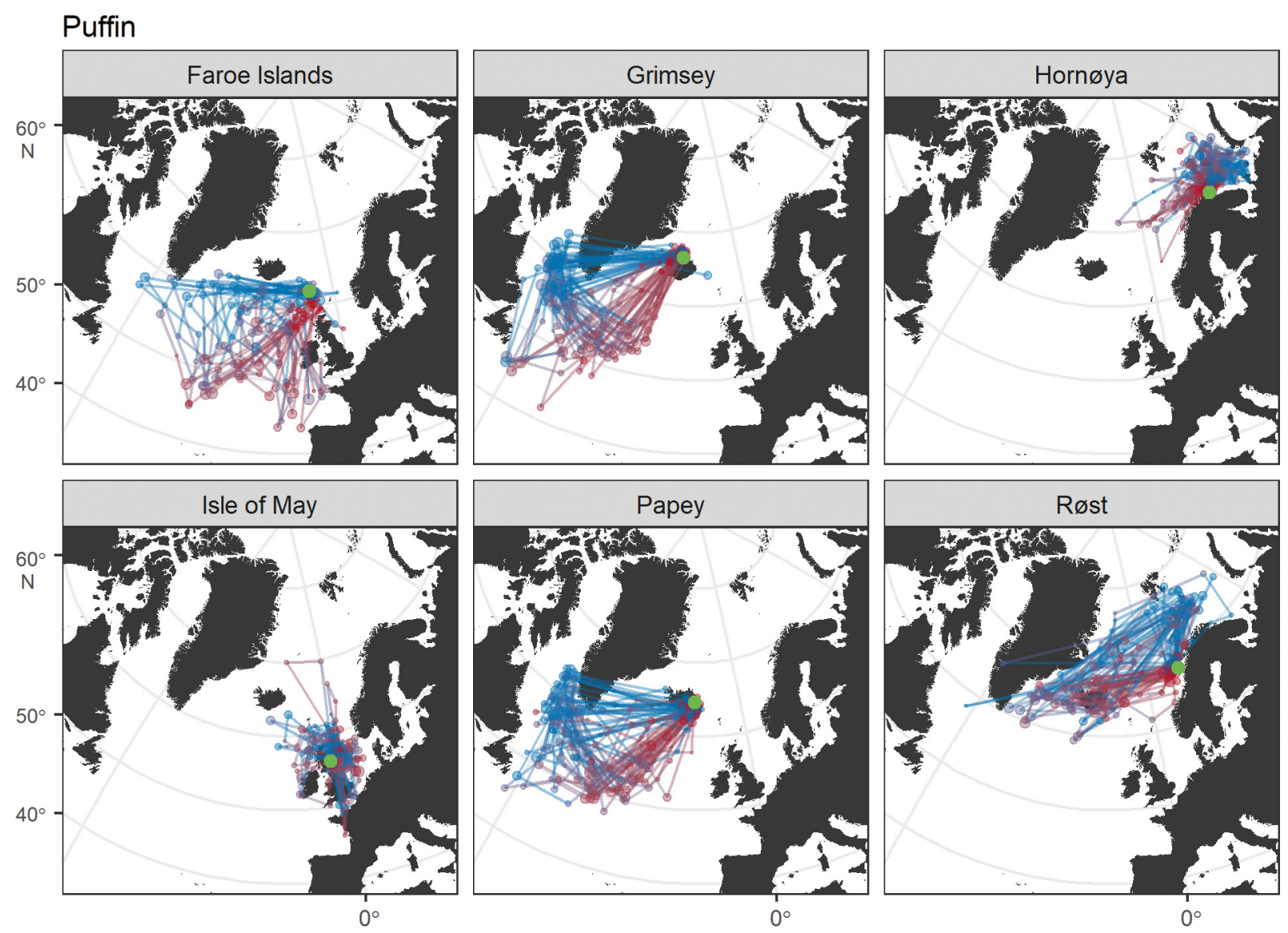

Duration (d) $\quad 50 \circ 100 \bigcirc 150 \circ 200$

Fig. 5. Examples of migration routes of Atlantic puffins from 6 colonies. One track is represented by segments linking the stationary areas (dots, centroid of the Lavielle segments, see example in Fig. 2G). Tracks are coloured along a blue (start) to red (end) gradient. Dot size is proportional to time spent in the area. Green dots: colonies. For each colony, 40 randomly selected tracks are presented except for the Faroe Islands, where all 32 tracks are presented. Other species are presented in Fig. S4

\subsection{Broad-scale migratory movements}

Interestingly, we found that the tracked birds of a given colony and species generally used preferred routes and reached specific wintering areas instead of dispersing in all possible directions from the colony (Figs. 5 \& S4). Similar results have been found in previous studies on the same species (Hatch et al. 2010, Frederiksen et al. 2012, Mosbech et al. 2012, Fayet et al. 2016, Merkel et al. 2021) and in many other seabird species such as Arctic terns, long-tailed skuas, sooty shearwaters and wandering albatrosses (Shaffer et al. 2006, Weimerskirch et al. 2015, van Bemmelen et al. 2017, Hromádková et al. 2020). Seabird migration patterns therefore did not match the dispersive migration definition (Newton 2007). Although some authors qualify the Atlantic puffin migration as dispersive (Guilford et al. 2011, Fayet et al. 2016), our results suggest that this may just be the case at certain study sites (e.g. Isle of May and
Hornøya, Fig. 5) and cannot be generalised to all colonies.

Our segmentation method performed well for individuals that had clear migratory movements between successive staging areas but was less effective for describing migration patterns of individuals remaining close to their colonies (residents) or those travelling constantly during the non-breeding season, as it did not filter these behaviours well. Nevertheless, we suggest that the method has some potential for further development and could be an important tool for understanding within- and between-colony variations in migration strategies. In particular, for some species such as fulmars or common guillemots, an improved classification would allow studying the relative importance of residents versus migrants in populations (partial migration) or to test the hypothesis that some populations might be facultative migrants. Defining concepts of residents and facultative migrants might, however, be challenging for pelagic seabirds (Newton 2012). 


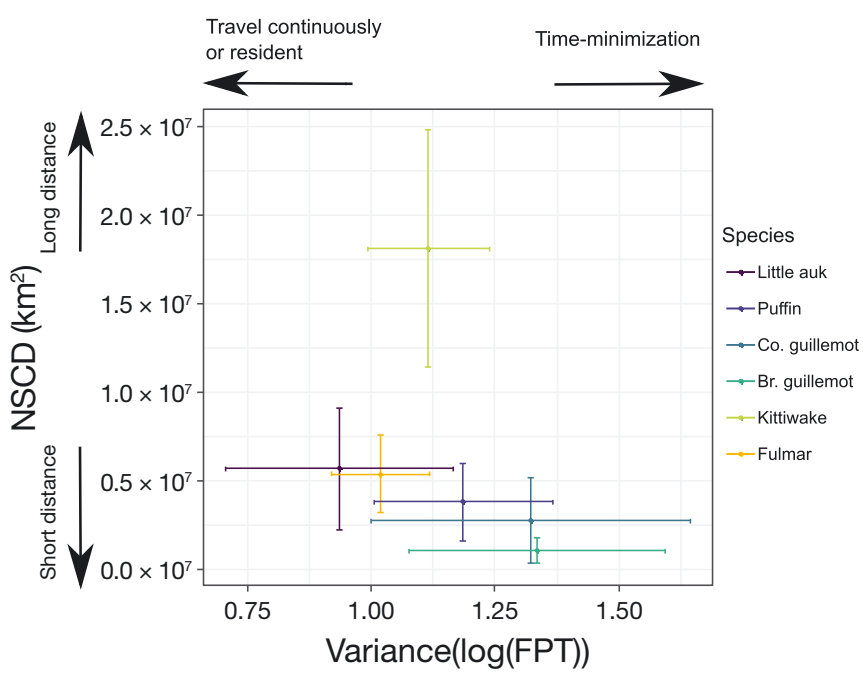

Fig. 6. Classification of migratory behaviour based on the maximum net-squared colony distance (NSCD, a measure of how far birds go from the colony) and the variance in the logarithm of the first-passage time (FPT, a measure of how variable the first passage time is; the higher it is, the more differences there are between migratory and stationary movements). Data: mean $\pm \mathrm{SD}$
Among the 6 species, individuals typically spent the winter at lower latitudes than their colonies, reflecting constraints in seasonal resources and climate, which are common causes of migration. Low temperatures increase seabird energy requirements during the non-breeding season and travelling to warmer, lower latitudes may be energetically advantageous (Fort et al. 2009, Amélineau et al. 2018, Dunn et al. 2020). At high latitudes, the polar night may constrain seabird distribution if light is required for daily activities (Pokrovsky et al. 2021), but this was not the case in most of the species we studied. Only kittiwakes did not encounter polar night, as they stayed below the Arctic Circle in winter, suggesting they may be more sensitive to a lack of daylight when foraging (McKnight et al. 2011). In contrast, at least some populations of all other 5 species spent the winter above the Arctic Circle; notably puffins, guillemots and fulmars in the Barents Sea and little auks in the Greenland Sea (Fig. S4). Similar observations were made for European shags in the Norwegian and Barents Seas (Moe et al. 2021 in this

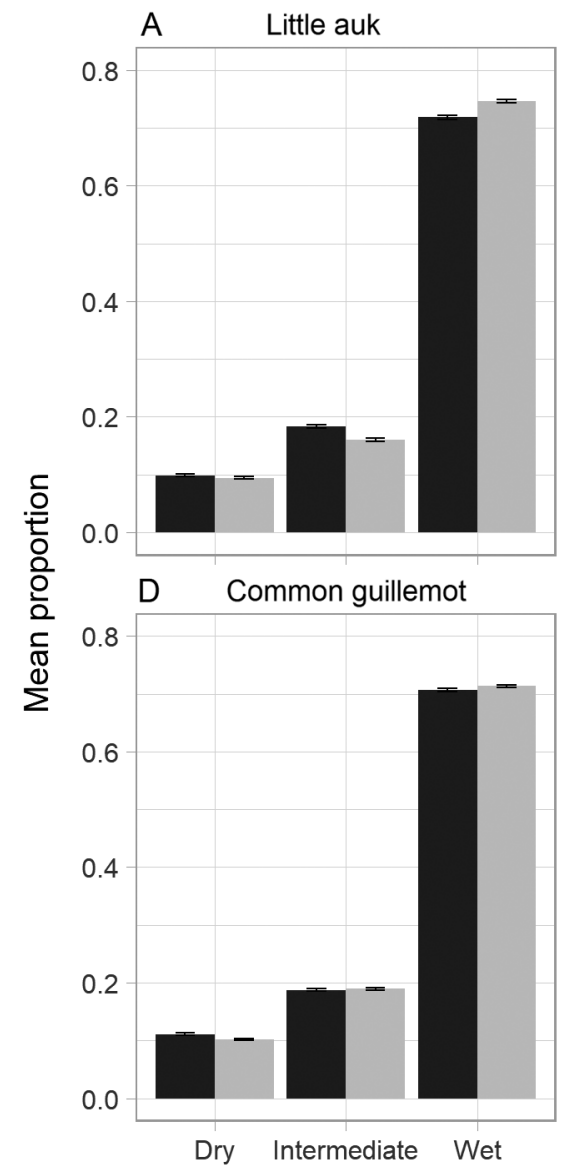

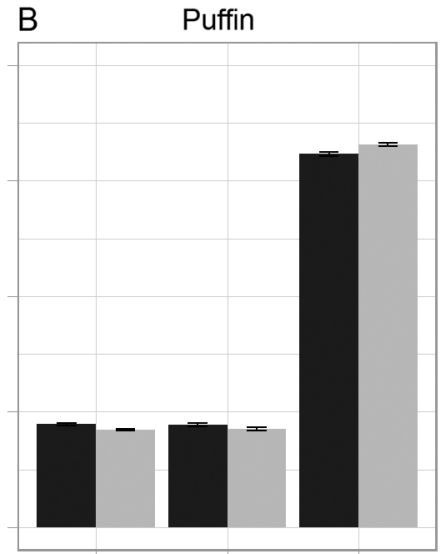

E Brünnich's guillemot

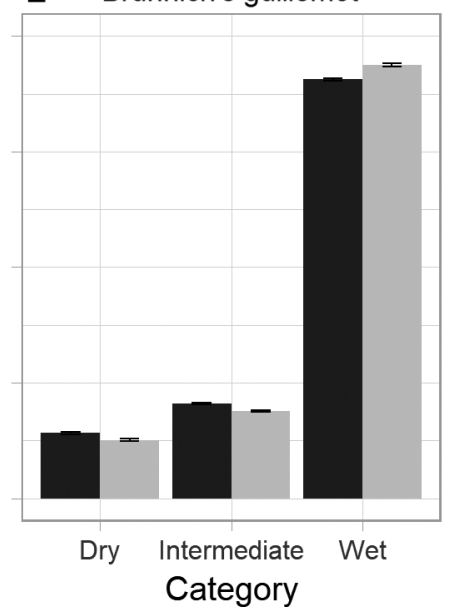

C Kittiwake

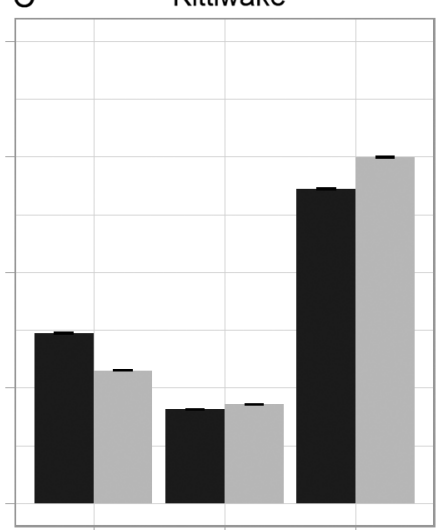

F

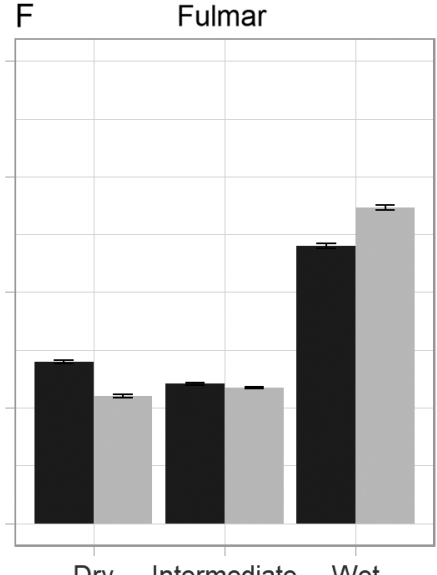

Dry Intermediate Wet

Fig. 7. Mean \pm SE proportion of time spent dry (flying), wet (resting) or intermediate (foraging; see Section 2.6) per day according to active migration (black) or stationary (light grey) segments 
Theme Section). Latitude may also indirectly reflect prey availability via changes in primary productivity. More broadly, prey availability ultimately determines where migrants spend time (Newton 2007, Alerstam \& Bäckman 2018) and likely constrains seabird migratory movements during the non-breeding season. However, other environmental constraints such as wind or distance between breeding and wintering sites also shape movement patterns in seabirds (González-Solís et al. 2009, Fort et al. 2012, Weimerskirch et al. 2015). Further investigations are now needed to understand how these factors interact to influence non-breeding migratory patterns of populations from different breeding locations.

\subsection{Differences in migratory movements and activity among species}

On a finer scale, we found different characteristics among the migratory movements of the 6 species. Some of these differences were better explained by family than species (time spent wet and time spent dry), and foraging strategy was not retained in any of the models. Differences between families might reflect wing morphology and flight characteristics. The 4 alcid species are divers, and their wing morphology is adapted to propulsion both underwater and in air through decreased wing area, increased wing loading and high energetic cost of flight (Elliott et al. 2013). In contrast, kittiwakes and fulmars are surface feeders with low wing loading and lower energetic costs of flight. Fulmars have a soaring flight that demands much less energy than flapping flight, while kittiwakes flight costs are intermediate (Watanabe 2016). These differences in the cost of flight were reflected in distance covered during active migration segments, where kittiwakes and fulmars travelled farther compared to alcids (Table 1). Kittiwakes and fulmars also exhibited more pronounced differences in apparent movement rate, time spent dry and intermediately wet and dry (proxy for flight and foraging respectively) between active migration and stationary periods. The fact that the alcids only slightly increased their time in flight when migrating underlines that they may be constrained by the amount of flight performed each day. On the other hand, the lower costs of flight in fulmars and kittiwakes might allow them to reach target areas more quickly with less need to forage on the way. It is also possible that alcids feeding in the water column have access to more prey than surface feeders at a given location (3D versus 2D foraging envi- ronment) and thus do not need to travel as far as the surface feeders to meet their energy requirements (Furness \& Tasker 2000, Passuni et al. 2016, Descamps et al. 2019). Moreover, body size also limits the theoretical maximum migration distance: Migration distance decreases with mass in flappingflight birds due to an increase in flight cost when body mass increases (Watanabe 2016). We observed this pattern to a certain extent for the alcids, with the smaller little auks and puffins migrating farther than the guillemots (Figs. 4 \& 6). Finally, differences in body size and wing loading among the alcids might also influence flight abilities (Spear \& Ainley 1997) and explain why the species factor performed better than the family factor to describe differences in apparent movement rate and sinuosity.

\subsection{Conservation implications}

Birds with a time-minimization strategy (Fig. 1A) usually fly over unfavourable habitat and geographical barriers without feeding and resting. In contrast, birds with a fly-and-forage strategy (Fig. 1B), such as the seabird species in our study, migrate over areas qualified as 'soft barriers' (Alerstam 2009). Our activity data highlight that birds crossing these areas during active migration continue to forage, although the energy acquisition may be at a slower rate than during stationary periods. In terms of conservation, it suggests that changes in conditions within these migratory corridors may have important consequences for these populations, particularly given the potential for carry-over effects to impact breeding (Daunt et al. 2014, Shoji et al. 2015). Our results confirm that migratory corridors should also be considered as important seabird areas, in addition to those areas where seabirds spend most time. These transitory areas are often used by different populations at different times of the year (Fort et al. 2012, Merkel et al. 2021). Furthermore, our results show that seabirds from different colonies and different species share similar migration routes. In particular, birds reaching the North-West Atlantic travelled along South-East Greenland in the autumn and came back by crossing the Atlantic Ocean south from Iceland. These routes are likely to follow wind and current regimes, which may reduce the energetic costs of migration and ultimately shape the geographic distribution of birds in the non-breeding season (Adams \& Flora 2010, Hromádková et al. 2020). The fact that several species share the same migration routes also increases the need to consider protection of 'migratory corridors' 
as a broader ecosystem unit rather than species-specific routes and areas. Non-breeding distributions of northern hemisphere seabirds are predicted to shift northwards in response to climate change (Hazen et al. 2013, Clairbaux et al. 2021). Furthermore, projected changes in wind regimes might also influence future migratory patterns (Weimerskirch et al. 2012). Together, these factors highlight the need to better understand links between changing environmental conditions and movement patterns, and how seabird conservation status may be impacted by ongoing environmental changes within important migratory corridors.

Acknowledgements. We thank all the fieldworkers for their hard work collecting data. Funding for this study was provided by the Norwegian Ministry for Climate and the Environment, the Norwegian Ministry of Foreign Affairs and the Norwegian Oil and Gas Association along with 8 oil companies through the SEATRACK project (www.seapop.no/en/ seatrack). Fieldwork in Norwegian colonies (incl. Svalbard and Jan Mayen) was supported by the SEAPOP program (www.seapop.no, grant no. 192141). The French Polar Institute (IPEV project 330 to O.C.) supported field operation for Kongsfjord kittiwakes. The work on the Isle of May was also supported by the Natural Environment Research Council (Award NE/R016429/1 as part of the UK-SCaPE programme delivering National Capability). We thank Maria Bogdanova for field support and data processing. Finally, we thank 3 anonymous reviewers for their help improving the first version of the manuscript.

\section{LITERATURE CITED}

Adams J, Flora S (2010) Correlating seabird movements with ocean winds: linking satellite telemetry with ocean scatterometry. Mar Biol 157:915-929

Alerstam T (2009) Flight by night or day? Optimal daily timing of bird migration. J Theor Biol 258:530-536

Alerstam T, Bäckman J (2018) Ecology of animal migration. Curr Biol 28:R968-R972

*Amélineau F, Fort J, Mathewson PD, Speirs DC and others (2018) Energyscapes and prey fields shape a North Atlantic seabird wintering hotspot under climate change. R Soc Open Sci 5:171883

Barraquand F, Benhamou S (2008) Animal movements in heterogeneous landscapes: identifying profitable places and homogeneous movement bouts. Ecology 89: 3336-3348

Benhamou S (2004) How to reliably estimate the tortuosity of an animal's path: straightness, sinuosity, or fractal dimension? J Theor Biol 229:209-220

Berg M, Linnebjerg JF, Taylor G, Ismar-Rebitz SMH and others (2019) Year-round distribution, activity patterns and habitat use of a poorly studied pelagic seabird, the fluttering shearwater Puffinus gavia. PLoS One 14:e0219986

Block BA, Jonsen ID, Jorgensen SJ, Winship AJ and others (2011) Tracking apex marine predator movements in a dynamic ocean. Nature 475:86-90

Bråthen VS, Moe B, Amélineau F, Ekker M and others (2021) An automated procedure (v2.0) to obtain positions from light-level geolocators in large-scale tracking of seabirds. A method description for the SEATRACK project. NINA Report 1893. Norwegian Institute for Nature Research, Trondheim. Available at https://brage.nina.no/ nina-xmlui/handle/11250/2735757

* Bunnefeld N, Börger L, van Moorter B, Rolandsen CM, Dettki H, Solberg EJ, Ericsson G (2011) A model-driven approach to quantify migration patterns: individual, regional and yearly differences. J Anim Ecol 80:466-476

Burnham KP, Anderson DR (2002) Model selection and multimodel inference: a practical information-theoretic approach, 2nd ed. Springer, New York, NY

* Calenge C (2006) The package 'adehabitat' for the R software: a tool for the analysis of space and habitat use by animals. Ecol Modell 197:516-519

Clairbaux M, Cheung WW, Mathewson P, Porter W and others (2021) Meeting Paris agreement objectives will temper seabird winter distribution shifts in the North Atlantic Ocean. Glob Change Biol 27:1457-1469

Cooke WW (1905) Routes of bird migration. Auk 22:1-11

C Croxall JP, Silk JRD, Phillips RA, Afanasyev V, Briggs DR (2005) Global circumnavigations: tracking year-round ranges of nonbreeding albatrosses. Science 307: $249-250$

* Daunt F, Reed TE, Newell M, Burthe S, Phillips RA, Lewis S, Wanless S (2014) Longitudinal bio-logging reveals interplay between extrinsic and intrinsic carry-over effects in a long-lived vertebrate. Ecology 95:2077-2083

* Descamps S, Ramírez F, Benjaminsen S, Anker-Nilssen T and others (2019) Diverging phenological responses of Arctic seabirds to an earlier spring. Glob Change Biol 25: 4081-4091

*Dias MP, Granadeiro JP, Catry P (2012) Do seabirds differ from other migrants in their travel arrangements? On route strategies of Cory's shearwater during its transequatorial journey. PLoS One 7:e49376

Dingle H, Drake VA (2007) What is migration? BioScience 57:113-121

* Dunn RE, Wanless S, Daunt F, Harris MP, Green JA (2020) A year in the life of a North Atlantic seabird: behavioural and energetic adjustments during the annual cycle. Sci Rep 10:5993

* Egevang C, Stenhouse IJ, Phillips RA, Petersen A, Fox JW, Silk JRD (2010) Tracking of Arctic terns Sterna paradisaea reveals longest animal migration. Proc Natl Acad Sci USA 107:2078-2081

Elliott KH, Ricklefs RE, Gaston AJ, Hatch SA, Speakman JR, Davoren GK (2013) High flight costs, but low dive costs, in auks support the biomechanical hypothesis for flightlessness in penguins. Proc Natl Acad Sci USA 110: 9380-9384

Fauchald P, Tveraa T (2003) Using first-passage time in the analysis of area-restricted search and habitat selection. Ecology 84:282-288

Fauchald P, Tarroux A, Bråthen VS, Descamps S and others (2019) Arctic-breeding seabirds' hotspots in space and time - a methodological framework for year-round modelling of environmental niche and abundance using light-logger data. NINA Report 1657. Norwegian Institute for Nature Research (NINA), Tromsø. http://hdl. handle.net/11250/2595504

F Fayet AL, Freeman R, Shoji A, Boyle D and others (2016) Drivers and fitness consequences of dispersive migration in a pelagic seabird. Behav Ecol 27:1061-1072

Fayet AL, Freeman R, Anker-Nilssen T, Diamond A and others (2017) Ocean-wide drivers of migration strategies 
and their influence on population breeding performance in a declining seabird. Curr Biol 27:3871-3878

Fort J, Porter WP, Grémillet D (2009) Thermodynamic modelling predicts energetic bottleneck for seabirds wintering in the northwest Atlantic. J Exp Biol 212:2483-2490

Fort J, Pettex E, Tremblay Y, Lorentsen SH and others (2012) Meta-population evidence of oriented chain migration in northern gannets (Morus bassanus). Front Ecol Environ 10:237-242

Frederiksen M, Moe B, Daunt F, Phillips RA and others (2012) Multicolony tracking reveals the winter distribution of a pelagic seabird on an ocean basin scale. Divers Distrib 18:530-542

Frederiksen M, Descamps S, Erikstad KE, Gaston AJ and others (2016) Migration and wintering of a declining seabird, the thick-billed murre Uria lomvia, on an ocean basin scale: conservation implications. Biol Conserv 200: 26-35

Furness RW, Tasker ML (2000) Seabird-fishery interactions: quantifying the sensitivity of seabirds to reductions in sandeel abundance, and identification of key areas for sensitive seabirds in the North Sea. Mar Ecol Prog Ser 202:253-264

Garthe S, Furness RW (2001) Frequent shallow diving by a Northern Fulmar feeding at Shetland. Waterbirds 24: 287-289

* González-Solís J, Croxall JP, Oro D, Ruiz X (2007) Transequatorial migration and mixing in the wintering areas of a pelagic seabird. Front Ecol Environ 5:297-301

González-Solís J, Felicisimo A, Fox JW, Afanasyev V, Kolbeinsson Y, Munoz J (2009) Influence of sea surface winds on shearwater migration detours. Mar Ecol Prog Ser 391:221-230

Grist H, Daunt F, Wanless S, Burthe SJ, Newell MA, Harris MP, Reid JM (2017) Reproductive performance of resident and migrant males, females and pairs in a partially migratory bird. J Anim Ecol 86:1010-1021

Guilford T, Freeman R, Boyle D, Dean B, Kirk H, Phillips R, Perrins C (2011) A dispersive migration in the Atlantic puffin and its implications for migratory navigation. PLoS One 6:e21336

* Hadjikyriakou TG, Nwankwo EC, Virani MZ, Kirschel ANG (2020) Habitat availability influences migration speed, refueling patterns and seasonal flyways of a fly-and-forage migrant. Mov Ecol 8:10

Hatch SA, Gill VA, Mulcahy DM (2010) Individual and colony-specific wintering areas of Pacific northern fulmars (Fulmarus glacialis). Can J Fish Aquat Sci 67: $386-400$

*Hazen EL, Jorgensen S, Rykaczewski RR, Bograd SJ and others (2013) Predicted habitat shifts of Pacific top predators in a changing climate. Nat Clim Chang 3: 234-238

Hedenström A (1993) Migration by soaring or flapping flight in birds: the relative importance of energy cost and speed. Philos Trans R Soc Lond B Biol Sci 342:353-361

KHomádková T, Pavel V, Flousek J, Briedis M (2020) Seasonally specific responses to wind patterns and ocean productivity facilitate the longest animal migration on Earth. Mar Ecol Prog Ser 638:1-12

Imlay TL, Saldanha S, Taylor PD (2020) The fall migratory movements of bank swallows, Riparia riparia: fly-andforage migration? Avian Conserv Ecol 15:2

Klaassen RH, Strandberg R, Hake M, Alerstam T (2008) Flexibility in daily travel routines causes regional varia- tion in bird migration speed. Behav Ecol Sociobiol 62: 1427-1432

Klaassen RHG, Ens BJ, Shamoun-Baranes J, Exo KM, Bairlein F (2012) Migration strategy of a flight generalist, the lesser black-backed gull Larus fuscus. Behav Ecol 23:58-68

Lavielle M (2005) Using penalized contrasts for the changepoint problem. Signal Process 85:1501-1510

Lecomte VJ, Sorci G, Cornet S, Jaeger A and others (2010) Patterns of aging in the long-lived wandering albatross. Proc Natl Acad Sci USA 107:6370-6375

Linnebjerg JF, Huffeldt NP, Falk K, Merkel FR, Mosbech A, Frederiksen $M$ (2014) Inferring seabird activity budgets from leg-mounted time-depth recorders. J Ornithol 155: 301-306

KLisovski S, Bauer S, Briedis M, Davidson SC and others (2020) Light-level geolocator analyses: a user's guide. J Anim Ecol 89:221-236

* Lorentsen SH, May R (2012) Inter-breeding movements of common guillemots (Uria aalge) suggest the Barents Sea is an important autumn staging and wintering area. Polar Biol 35:1713-1719

*Mackley EK, Phillips RA, Silk JRD, Wakefield ED, Afanasyev V, Fox JW, Furness RW (2010) Free as a bird? Activity patterns of albatrosses during the nonbreeding period. Mar Ecol Prog Ser 406:291-303

McFarlane Tranquilla LA, Montevecchi WA, Hedd A, Fifield DA and others (2013) Multiple-colony winter habitat use by murres Uria spp. in the Northwest Atlantic Ocean: implications for marine risk assessment. Mar Ecol Prog Ser 472:287-303

McKnight A, Irons DB, Allyn AJ, Sullivan KM, Suryan RM (2011) Winter dispersal and activity patterns of postbreeding black-legged kittiwakes Rissa tridactyla from Prince William Sound, Alaska. Mar Ecol Prog Ser 442: 241-253

McLean DJ, Volponi MAS (2018) Trajr: an R package for characterisation of animal trajectories. Ethology 124: $440-448$

* Merkel B, Descamps S, Yoccoz NG, Grémillet D and others (2021) Strong migratory connectivity across meta-populations of sympatric North Atlantic seabirds. Mar Ecol Prog Ser 476:173-188

*Moe B, Daunt F, Bråthen VS, Barrett RT and others (2021) Twilight foraging enables European shags to survive the winter across their latitudinal range. Mar Ecol Prog Ser 476:145-157

Mosbech A, Johansen KL, Bech NI, Lyngs P and others (2012) Inter-breeding movements of little auks Alle alle reveal a key post-breeding staging area in the Greenland Sea. Polar Biol 35:305-311

Newton I (2007) The migration ecology of birds. Academic Press, London

* Newton I (2012) Obligate and facultative migration in birds: ecological aspects. J Ornithol 153:171-180

* Orben RA, Kokubun N, Fleishman AB, Will AP and others (2018) Persistent annual migration patterns of a specialist seabird. Mar Ecol Prog Ser 593:231-245

* Passuni G, Barbraud C, Chaigneau A, Demarcq H and others (2016) Seasonality in marine ecosystems: Peruvian seabirds, anchovy, and oceanographic conditions. Ecology 97:182-193

* Pérez C, Granadeiro JP, Dias MP, Alonso H, Catry P (2014) When males are more inclined to stay at home: insights into the partial migration of a pelagic seabird provided by geolocators and isotopes. Behav Ecol 25:313-319 
Phillips RA, Silk JRD, Croxall JP, Afanasyev V, Briggs DR (2004) Accuracy of geolocation estimates for flying seabirds. Mar Ecol Prog Ser 266:265-272

Pinheiro J, Bates D, DebRoy S, Sarkar D, R Core Team (2020) nlme: linear and nonlinear mixed effects models. R package version 3.1-152. https://CRAN.R-project.org/ package $=$ nlme

Pokrovsky I, Kölzsch A, Sherub S, Fiedler W and others (2021) Longer days enable higher diurnal activity for migratory birds. J Anim Ecol 90:2161-2171

R Core Team (2020) R: a language and environment for statistical computing. R Foundation for Statistical Computing, Vienna. www.r-project.org

Ropert-Coudert Y, Wilson RP (2005) Trends and perspectives in animal-attached remote sensing. Front Ecol Environ 3:437-444

Shaffer SA, Tremblay Y, Weimerskirch H, Scott D and others (2006) Migratory shearwaters integrate oceanic resources across the Pacific Ocean in an endless summer. Proc Natl Acad Sci USA 103:12799-12802

Shoji A, Aris-Brosou S, Culina A, Fayet A and others (2015) Breeding phenology and winter activity predict subsequent breeding success in a trans-global migratory seabird. Biol Lett 11:20150671

Spear LB, Ainley DG (1997) Flight speed of seabirds in relation to wind speed and direction. Ibis 139:234-251

* Spitz DB, Hebblewhite M, Stephenson TR (2017) 'MigrateR': extending model-driven methods for classifying and quantifying animal movement behavior. Ecography 40: 788-799

Strandberg R, Alerstam T (2007) The strategy of fly-and-for- age migration, illustrated for the osprey (Pandion haliaetus). Behav Ecol Sociobiol 61:1865-1875

Technitis G, Othman W, Safi K, Weibel R (2015) From A to B, randomly: a point-to-point random trajectory generator for animal movement. Int J Geogr Inf Sci 29:912-934

* van Bemmelen R, Moe B, Hanssen SA, Schmidt NM and others (2017) Flexibility in otherwise consistent nonbreeding movements of a long-distance migratory seabird, the long-tailed skua. Mar Ecol Prog Ser 578:197-211

* Watanabe YY (2016) Flight mode affects allometry of migration range in birds. Ecol Lett 19:907-914

* Weimerskirch H, Louzao M, de Grissac S, Delord K (2012) Changes in wind pattern alter albatross distribution and life-history traits. Science 335:211-214

*Weimerskirch H, Delord K, Guitteaud A, Phillips RA, Pinet P (2015) Extreme variation in migration strategies between and within wandering albatross populations during their sabbatical year and their fitness consequences. Sci Rep 5:8853

Wilson RP, Ducamp JJ, Rees WG, Culik BM, Niekamp K (1992) Estimation of location: global coverage using light intensity. In: Priede IG, Swift SM (eds) Wildlife telemetry: remote monitoring and tracking of animals. Ellis Horwood Ltd, Chichester, p 131-134

* Yurkowski DJ, Auger-Méthé M, Mallory ML, Wong SNP and others (2019) Abundance and species diversity hotspots of tracked marine predators across the North American Arctic. Divers Distrib 25:328-345

Zuur AF, Ieno EN (2016) A protocol for conducting and presenting results of regression-type analyses. Methods Ecol Evol 7:636-645 


\section{F. Amélineau ${ }^{1, *}$, B. Merkel ${ }^{1,22}$, A. Tarroux ${ }^{2}$, S. Descamps ${ }^{1}$, T. Anker-Nilssen ${ }^{3}$,} O. Bjørnstad ${ }^{4}$, V. S. Bråthen ${ }^{3}$, O. Chastel ${ }^{5}$, S. Christensen-Dalsgaard ${ }^{5}$, J. Danielsen ${ }^{6}$, F. Daunt ${ }^{7}$, N. Dehnhard ${ }^{3}$, M. Ekker ${ }^{8}$, K. E. Erikstad ${ }^{2}$, A. Ezhov ${ }^{9}$, P. Fauchald ${ }^{2}$, M. Gavrilo ${ }^{10,} 11,23$, G. T. Hallgrimsson ${ }^{12}$, E. S. Hansen ${ }^{13}$, M. P. Harris ${ }^{7}$, M. Helberg ${ }^{14}$, H. H. Helgason ${ }^{1,24}$, M. K. Johansen ${ }^{1}$, J. E. Jónsson ${ }^{15}$, Y. Kolbeinsson ${ }^{16}$, Y. Krasnov ${ }^{9}$, M. Langset ${ }^{3}$, S. H. Lorentsen ${ }^{3}$, E. Lorentzen ${ }^{1}$, M. V. Melnikov ${ }^{17}{ }^{17}$ B. Moe $^{3}$, M. A. Newell ${ }^{7}$, B. Olsen ${ }^{6}$, T. Reiertsen ${ }^{2}$, G. H. Systad ${ }^{18}$, P. Thompson ${ }^{19}$, T. L. Thórarinsson ${ }^{16}$, E. Tolmacheva ${ }^{20}$, S. Wanless ${ }^{7}$, K. Wojczulanis-Jakubas ${ }^{21}$, J. Åström ${ }^{3}$, H. Strøm ${ }^{1}$

${ }^{1}$ Norwegian Polar Institute, Fram Centre, 9296 Tromsø, Norway ${ }^{2}$ Norwegian Institute for Nature Research, Fram Centre, 9296 Tromsø, Norway

${ }^{3}$ Norwegian Institute for Nature Research, 7485 Trondheim, Norway

${ }^{4}$ Karmøy Ringmerkingsgruppe, 4280 Skudeneshavn, Norway

${ }^{5}$ Centre d'Etudes Biologiques de Chizé, UMR7372, CNRS-Université La Rochelle, 79360 Villiers en Bois, France

${ }^{6}$ Faroe Marine Research Institute, 100 Tórshavn, Faroe Islands

${ }^{7}$ UK Centre for Ecology \& Hydrology, Penicuik, EH26 0QB, UK

${ }^{8}$ Norwegian Environment Agency, 7485 Trondheim, Norway

${ }^{9}$ Murmansk Marine Biological Institute, 183010 Murmansk, Russia

${ }^{10}$ National Park Russian Arctic, 163069 Archangelsk, Russia

${ }^{11}$ Association Maritime Heritage, 199106 Saint Petersburg, Russia

${ }^{12}$ Faculty of Life and Environmental Sciences, University of Iceland, 102 Reykjavik, Iceland

${ }^{13}$ South Iceland Nature Research Centre, 900 Vestmannaeyjar, Iceland

${ }^{14}$ Østfold University College, 1757 Halden, Norway

${ }^{15}$ University of Iceland's Research Centre at Snæfellsnes, 340 Stykkishólmur, Iceland

${ }^{16}$ Northeast Iceland Nature Research Centre, 640 Húsavík, Iceland

${ }^{17}$ Lipetsk State Pedagogical University, 398020 Lipetsk, Russia

${ }^{18}$ Norwegian Institute for Nature Research, 5006 Bergen, Norway

${ }^{19}$ Lighthouse Field Station, School of Biological Sciences, University of Aberdeen, IV11 8YL, UK

${ }^{20}$ Kandalaksha State Nature Reserve, 184042 Kandalaksha, Russia

${ }^{21}$ University of Gdansk, 80-309 Gdansk, Poland

${ }^{22}$ Present address: Akvaplan-niva, Fram Centre, 9296 Tromsø, Norway

${ }^{23}$ Present address: Arctic and Antarctic Research Institute, 198397 Saint Petersburg, Russia

${ }^{24}$ Present address: East Iceland Nature Research Centre, 740 Neskaupstaður, Iceland

Editorial responsibility: Samantha Patrick (Guest Editor), Liverpool, UK

Reviewed by: 3 anonymous referees
Submitted: December 17, 2020

Accepted: August 17, 2021

Proofs received from author(s): October 12, 2021 